\title{
Z BADAŃ NAD NEOLITYZACJĄ POLSKI ŚRODKOWEJ. POZOSTALOŚCI OSADNICTWA KULTURY PUCHARÓW LEJKOWATYCH ZE STANOWISKA POLESIE 1, GM. LYSZKOWICE
}

\author{
STUDY OF NEOLITHISATION OF CENTRAL POLAND. \\ REMAINS OF THE FUNNEL BEAKER CULTURE SETTLEMENT \\ FROM SITE POLESIE 1, COM. ŁYSZKOWICE
}

\author{
Seweryn Rzepecki \\ Instytut Archeologii, Uniwersytet Łódzki \\ ul. Uniwersytecka 3, 90-137 Łódź, Poland \\ rzepecki@uni.lodz.pl
}

\begin{abstract}
The article presents the results of the study of the Funnel Beaker culture settlement at site Polesie 1, com. Łyszkowice. There have been recognised very damaged remnants of a settlement and campsites of Neolithic communities. The author of the study links them to the process of colonisation, which had started in Kujawy or eastern Wielkopolska.
\end{abstract}

KEY WORDS: Funnel Beaker culture, Neolithisation, Polesie, central Poland.

Stanowisko Polesie 1, gm. Łyszkowice, znane jest z głównie z rozległego kompleksu związanego z osadami i cmentarzyskami kultury trzcinieckiej (Górski, Makarowicz, Wawrusiewicz 2011). Cytowana praca zawiera również szczegółowe omówienie warunków środowiskowych osadnictwa pradziejowego. Ograniczając się do wątków najbardziej podstawowych, trzeba zwrócić przede wszystkim uwagę na cechy litologii stanowiska. Budują je utwory piaszczyste, niekiedy z udziałem żwirów i mułków, a w południowo-zachodnim skraju stanowiska również gliny zwałowe. Znaczny udział piasków determinował w warunkach odlesienia uruchomienie i dynamiczny przebieg procesów niszczenia stanowiska na skutek erozji stoków oraz deflacji (Twardy, Forysiak 2011, s. 229-244). Intensywność osadnictwa pradziejowego (kultura trzciniecka i przeworska) oraz tego związanego z wczesnośredniowieczną, a szczególnie - nowożytną i współczesną - rolniczą eksploatacją terenu 
powoduje, że stanowisko jest doskonałym przykładem archeologicznego palimpsestu (Bailey 2007; Rzepecki 2014a), w którym kolejne epizody aktywności deformowały i nieodwracalnie niszczyły starsze ślady zasiedlenia. Obserwacji archeologicznej podlegał zatem sedyment o charakterze wybitnie „kompaktowym”, w którym źródła pradziejowe, średniowieczne, nowożytne i współczesne zostały skompresowane $\mathrm{w}$ jeden poziom stratygraficzny.

Powyższe uwagi miały na celu unaocznienie wysokiego stopnia przekształcenia reliktów osadnictwa kultury pucharów lejkowatych (dalej: KPL) z omawianego stanowiska. W oczywisty sposób utrudnia ono - lub wręcz wyklucza - możliwość prowadzenia wielu analiz, np. behawioralnych (por. Wilkostowo 23/24, gm. Aleksandrów Kujawski - zob. Rzepecki 2014). Mimo zarysowanych ograniczeń Polesie 1 nadal stanowi interesujący i inspirujący zestaw źródeł. W niniejszym tekście nakreślę wyniki analiz przestrzennych i funkcjonalnych osadnictwa oraz charakterystykę cech garncarstwa i wytwórczości krzemieniarskiej (Domańska, Wąs 2010). Informacje te zostaną wykorzystane do zarysowania pozycji stanowiska w procesie neolityzacji terenów Polski środkowej.

\section{WARSTWA I OBIEKTY NIERUCHOME}

Zdecydowana większość źródeł KPL (ok. 95\% ceramiki) została zarejestrowana poza wypełniskami obiektów nieruchomych, w subpowierzchniowym poziomie glebowym intensywnie przekształconym na skutek orki. Należy uznać, że w swojej masie materiały ruchome podlegały redepozycjom o charakterze pionowym. Także obserwowane strefy aglomeracji ceramiki (ryc. 1) są jedynie aproksymacją pierwotnych układów skupień. Ich zadokumentowana forma jest w znacznej mierze efektem niszczącego wpływu dróg i funkcjonowania nielegalnych wybierzysk piasku (odcinek K).

Można przyjąć, że centrum obszaru zasiedlonego znajdowało się na terenie odcinków C i K stanowiska, m.in. zarejestrowano tam ok. 75\% ceramiki KPL (ryc. 1). Tworzą one, wraz z pograniczem hektarów B, D, J i L, względnie zwartą przestrzeń o powierzchni ok. 1,5 ha. Wymowa występowania pojedynczych fragmentów ceramiki poza tym obszarem jest niezbyt klarowna. W wielu przypadkach (np. odcinek D lub L) może być to rezultat redeponowania materiału. Alternatywnie można wskazać na ich związek z funkcjonowaniem niewielkich i krótkotrwałych obozowisk pomocniczych. To przypuszczenie wydaje się szczególnie wiarygodne w odniesieniu np. do hektara M. Jest on znacznie oddalony od wspomnianej wyżej aglomeracji, jednocześnie zachodnia część stanowiska cechuje się podwyższoną wilgotnością gleby, co powoduje jej nieco większą przydatność rolniczą. 


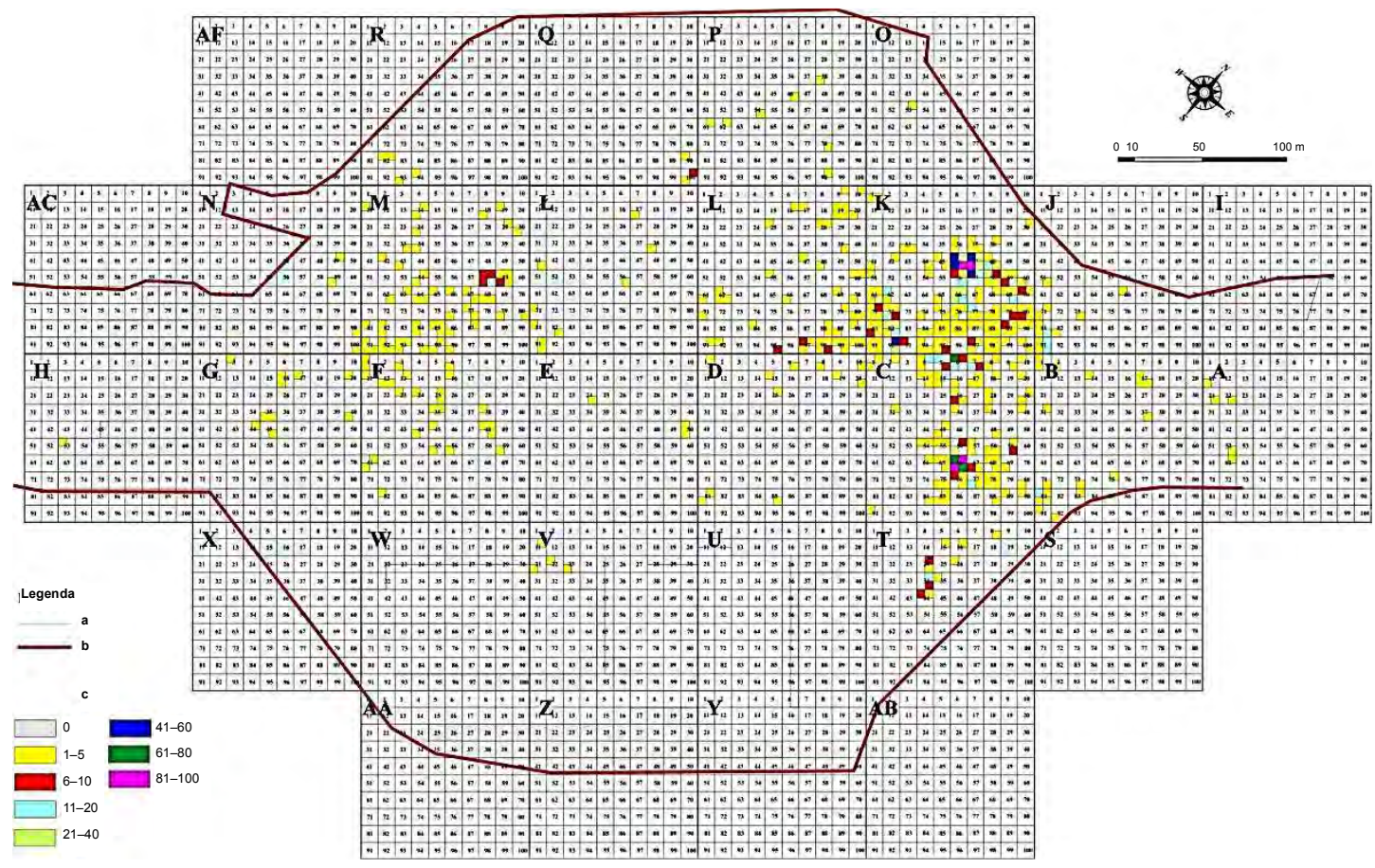

Ryc. 1. Polesie 1, gm. Łyszkowice. Dyspersja ceramiki kultury pucharów lejkowatych. Legenda: $\mathrm{a}$ - granice wykopów archeologicznych; $\mathrm{b}$ - granica inwestycji; $\mathrm{c}$ - liczba fragmentów ceramiki w obrębie ,warstwy”

Fig. 1. Polesie 1, com. Łyszkowice. Dispersion of TRB pottery. Legend: a - borders of trenches; $\mathrm{b}$ - borders of the development; $\mathrm{c}$ - number of potsherds within a "layer"

W takim kontekście konieczne jest zastosowanie wyostrzonych kryteriów identyfikacji neolitycznych źródeł nieruchomych (por. Domańska i in. 2012, s. 186-187). W preferowanym tu ujęciu można przypisać KPL 13 obiektów reprezentujących następujące kategorie funkcjonalne: domy, jamy zasobowe oraz jamy o nieokreślonym przeznaczeniu gospodarczym. Wszystkie znajdowały się w obrębie hektarów C i K (ryc. 2).

Jako relikt obiektu mieszkalnego potraktowano obiekt C1035. Został on rozpoznany jako bardzo wyraźne skupisko polepy. Składa się na nie 3470 grudek przepalonej gliny o łącznej wadze 10,41 kg. Analiza makroskopowa tych grudek nie wskazała na zastosowanie jakiejkolwiek domieszki, poza naturalnie występującymi ziarnami piasku. $Z$ osad KPL z terenu Niżu Polskiego pochodzi wiele analogii dla tego rodzaju struktur (np. Balcer 2012; Pelisiak 2003; Rybicka 2004; Rzepecki 2014). Stanowią one pozostałości domostw o kompozytowej, tzn. drewniano-glinianej konstrukcji ścian. W przypadku omawianego obiektu przekonanie o jego związku z KPL opiera się na podobieństwie do reliktów domostw opisanych w cy- 

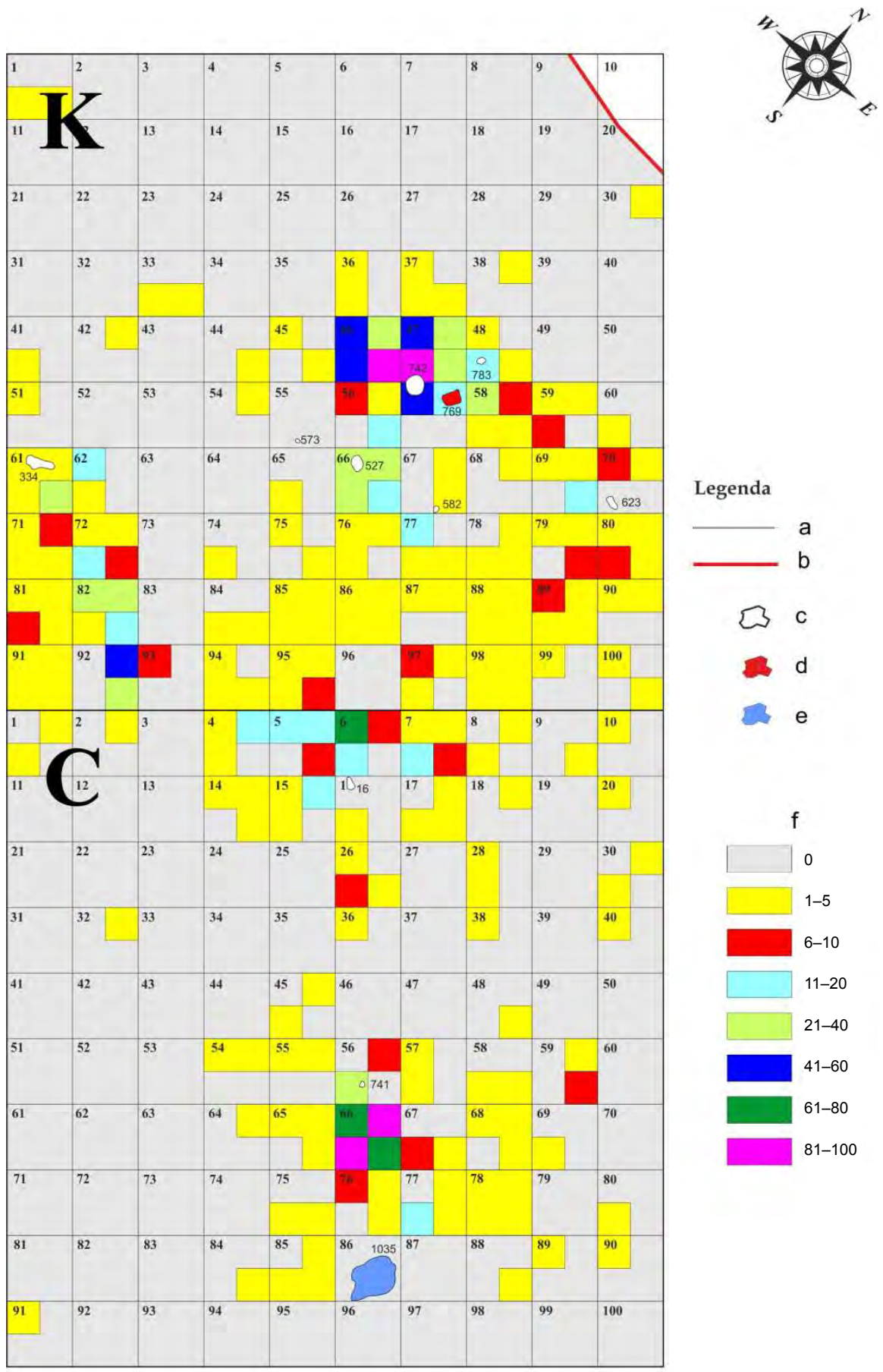

Legenda
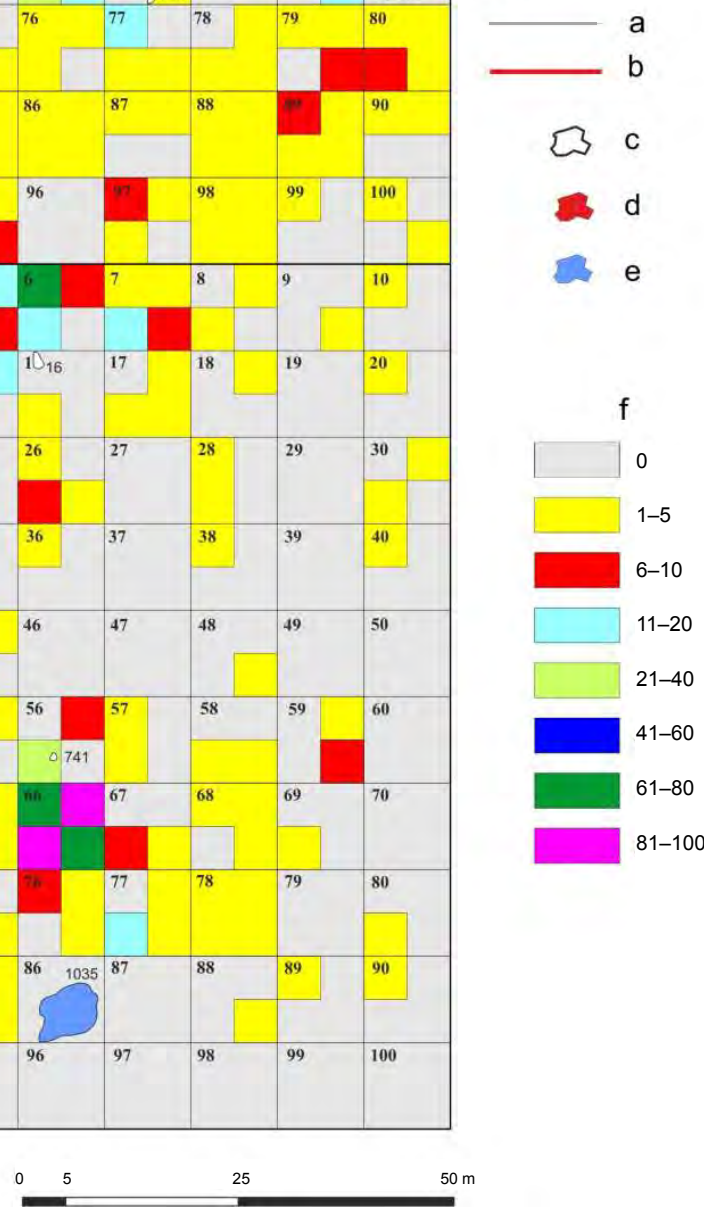
towanych pracach oraz braku $\mathrm{w}$ tej strefie stanowiska pozostałości osadnictwa $\mathrm{z}$ innych etapów jego okupacji.

Pełnienie funkcji zasobowych przypisano obiektowi K769 (Domańska i in. 2012, s. 186-187). Posłużono się w tym przypadku kryteriami wypracowanymi w trakcie analizy osady w Wilkostowie 23/24 (Rzepecki 2014, s. 123). Jako wskaźniki posłużyły: regularność rzutu poziomego, płaskie dno oraz regularność i symetria ścian tego obiektu. Sugeruje to zastosowanie okładziny drewnianej lub wykonanej z plecionki dla zabezpieczenia ścian. W trakcie niwelacji niecka jamy została wykorzystana jako doraźne śmietnisko, do którego trafiło kilkanaście fragmentów ceramiki o łącznej wadze $3845 \mathrm{~g}$.

Pozostałe obiekty (C16, C741, K334, K527, K742, K573, K623, KK782, K783, K171, K587) określono jako jamy o niesprecyzowanym przeznaczeniu gospodarczym. Ich cechami charakterystycznymi są nieckowate profile oraz zwykle bardzo niewielka miąższość, najczęściej obserwowano jedynie ich spągi - stąd niewielkie nasycenie źródłami ceramicznymi.

\section{CERAMIKA}

Na stanowisku odkryto 3676 fragmentów ceramiki KPL o łącznej wadze 46972 g. Ze względu na konwencję tekstu przedstawię jedynie najistotniejsze cechy tego zbioru.

Znaczne rozdrobnienie nie pozwala na pełną rekonstrukcję form naczyń. Wystarczające wydaje się jednak zaakcentowanie obecności pucharów lejkowatych (np. ryc. 6:2, 4; 9:1), pucharów moździerzowatych (ryc. 5:13), amfor (ryc. 3:7; 9:2) oraz flasz z kryzą (ryc. 7:8), garnków (ryc. 4:10, 8:7) i mis/waz (ryc. 7:2). Tworzą one zestaw dość dobrze udokumentowany dla rozwiniętego odcinka fazy wióreckiej grupy wschodniej KPL (zob. np. Kośko, Szmyt 2006; Rybicka 2004; Rzepecki 2014; Wierzbicki 2013). Z tą diagnozą współgra ocena zdobnictwa znanego ze 186 fragmentów naczyń.

Ryc. 2. Polesie 1, gm. Łyszkowice. Osadnictwo kultury pucharów lejkowatych w obrębie odcinków C i K. Legenda: a - granica wykopów archeologicznych; b - granica inwestycji; c - jamy gospodarcze o nieokreślonym przeznaczeniu; $\mathrm{d}$ - jama zasobowa; e - obiekt mieszkalny; $\mathrm{f}$ - liczba fragmentów ceramiki w obrębie ,warstwy"

Fig. 2. Polesie 1, com. Łyszkowice. Settlement of the TRB culture within sections C and K. Legend: $\mathrm{a}$ - borders of trenches; $\mathrm{b}$ - borders of the development; $\mathrm{c}$ - pits of undetermined function; $\mathrm{d}$ - storage pit; $\mathrm{e}-\mathrm{dwelling}$ feature; $\mathrm{f}-$ number of potsherds within a "layer" 


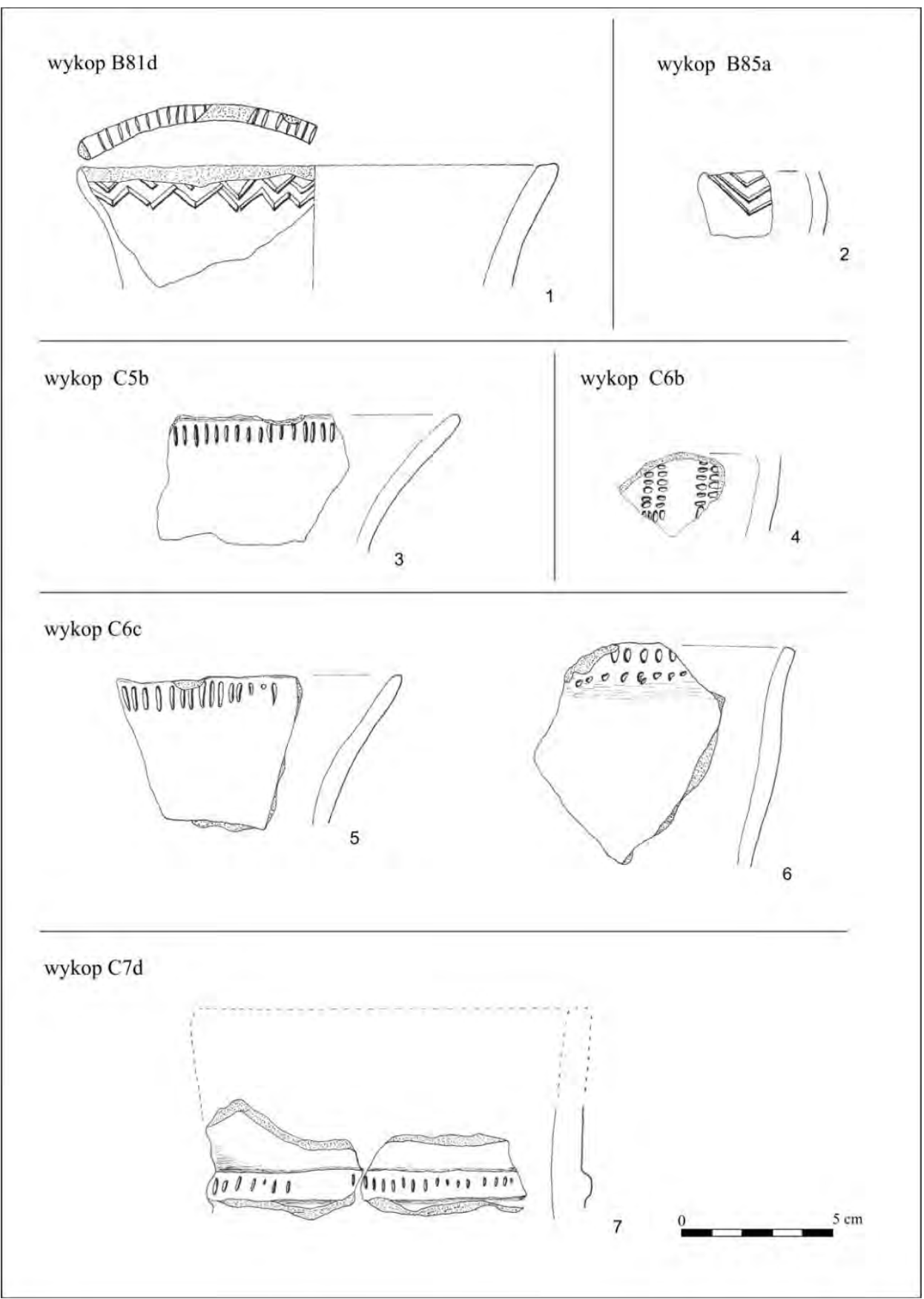

Ryc. 3. Polesie 1, gm. Łyszkowice. Wybór ceramiki kultury pucharów lejkowatych Fig. 3. Polesie 1, com. Łyszkowice. Selection of TRB pottery 


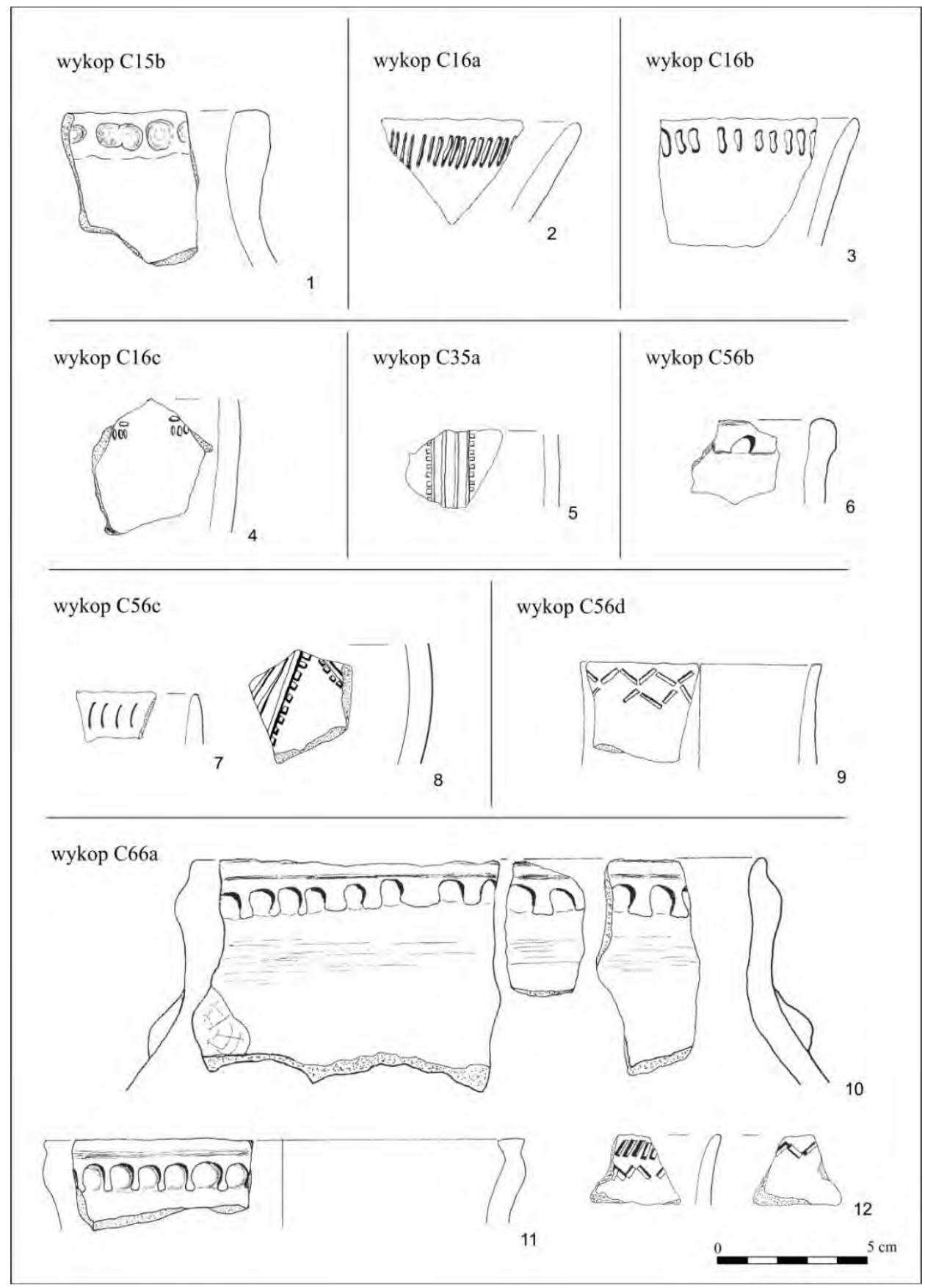

Ryc. 4. Polesie 1, gm. Łyszkowice. Wybór ceramiki kultury pucharów lejkowatych Fig. 4. Polesie 1, com. Łyszkowice. Selection of TRB pottery 
wykop C66b
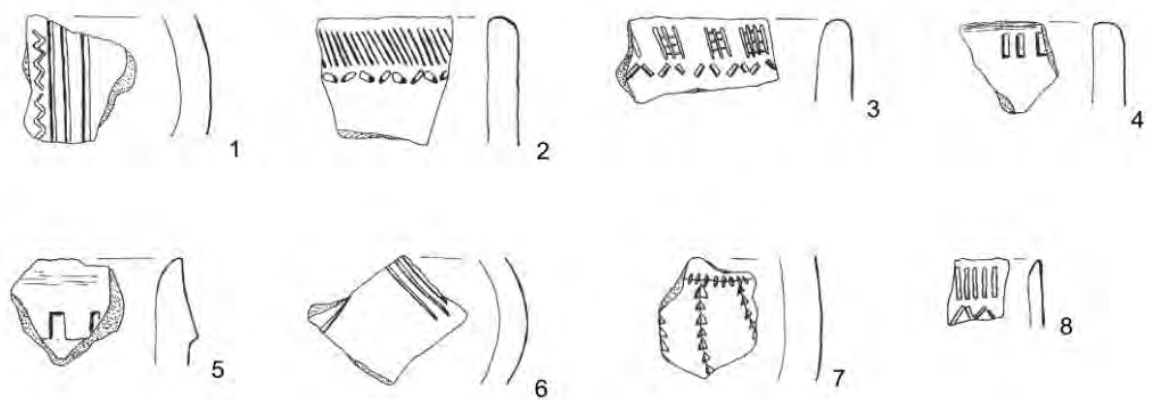

wykop C76a
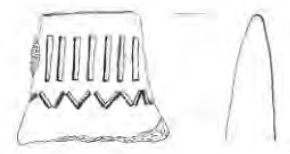

9

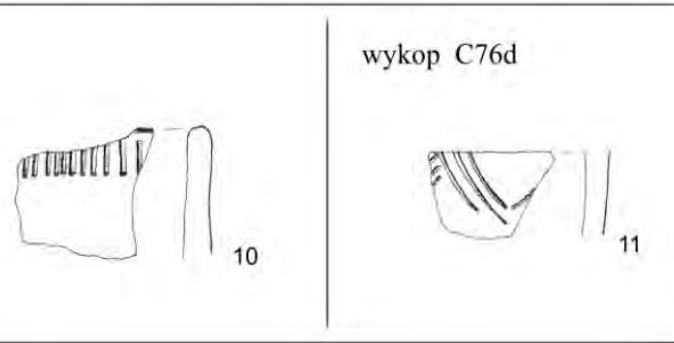

wykop K46a

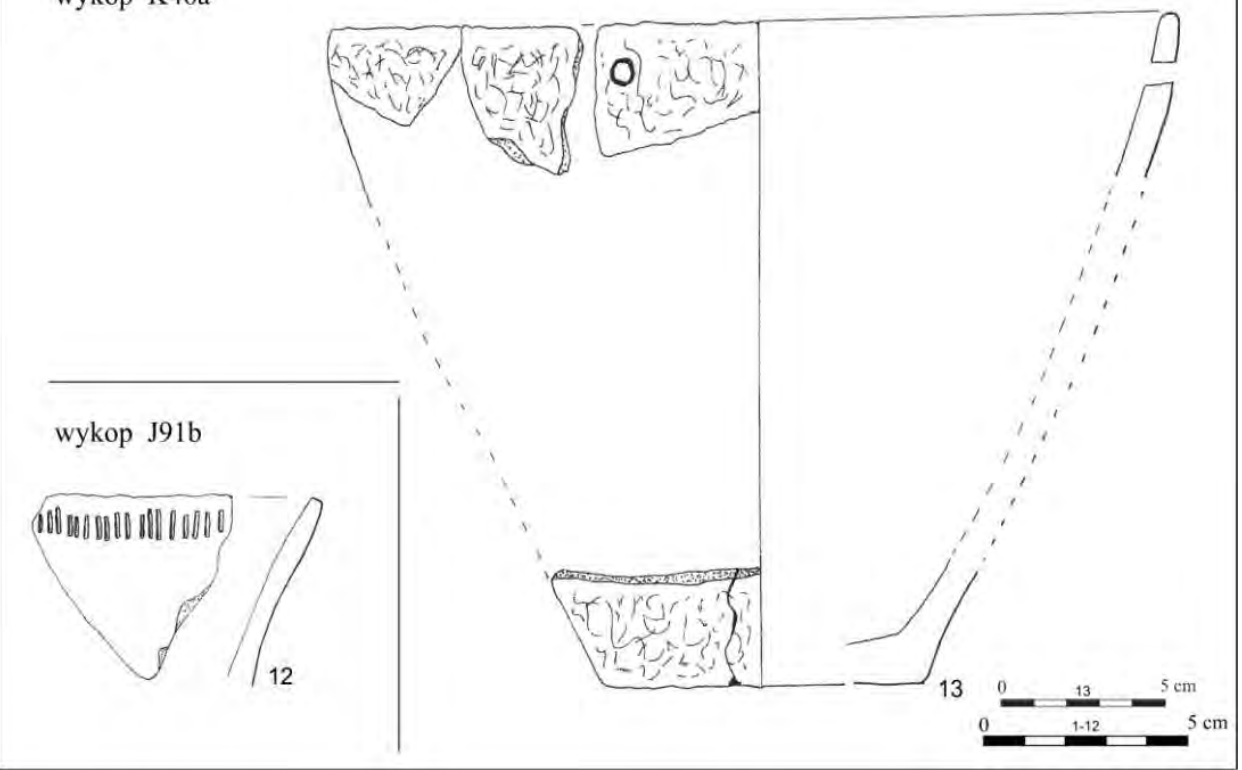

Ryc. 5. Polesie 1, gm. Łyszkowice. Wybór ceramiki kultury pucharów lejkowatych Fig. 5. Polesie 1, com. Łyszkowice. Selection of TRB pottery 
wykop K46d

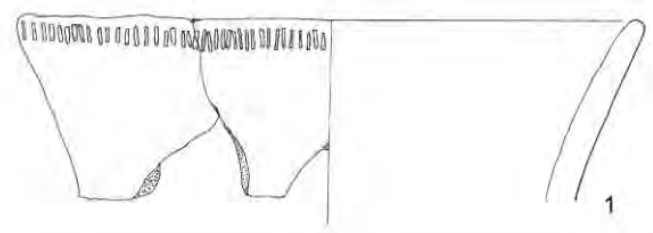

wykop K47 (skupisko 34)
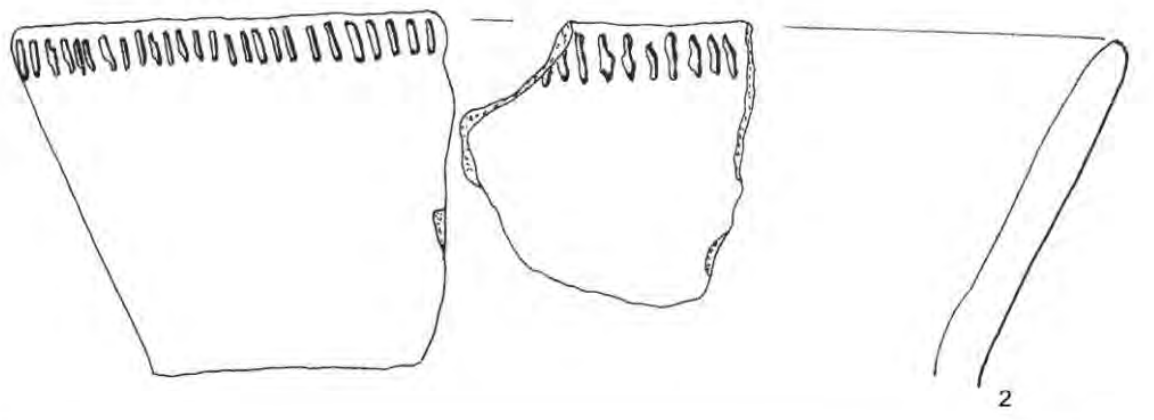

wykop K47 (skupisko 66)

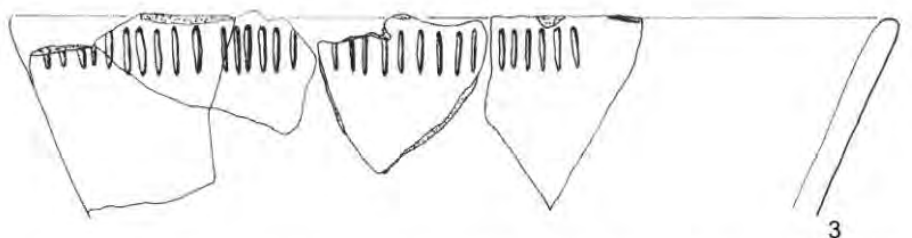

3

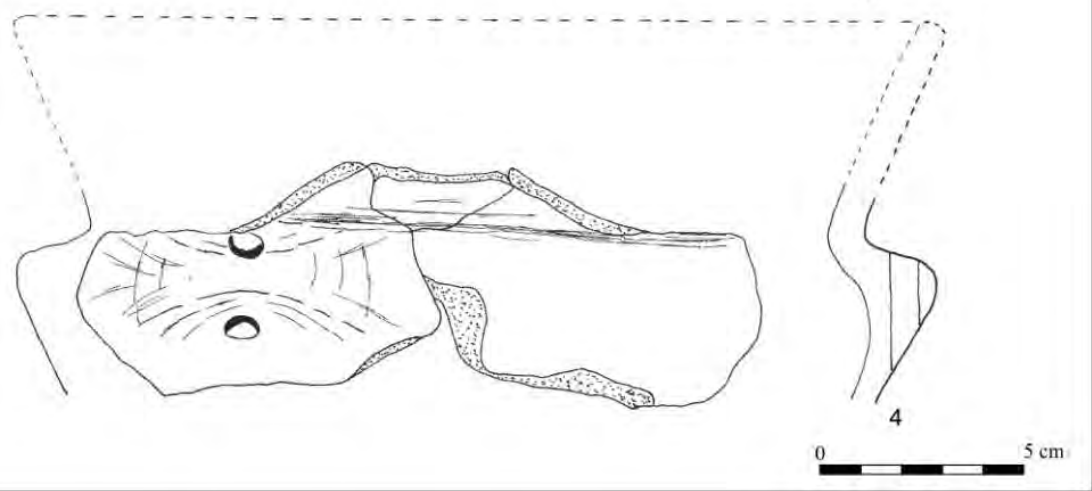

Ryc. 6. Polesie 1, gm. Łyszkowice. Wybór ceramiki kultury pucharów lejkowatych Fig. 6. Polesie 1, com. Łyszkowice. Selection of TRB pottery 


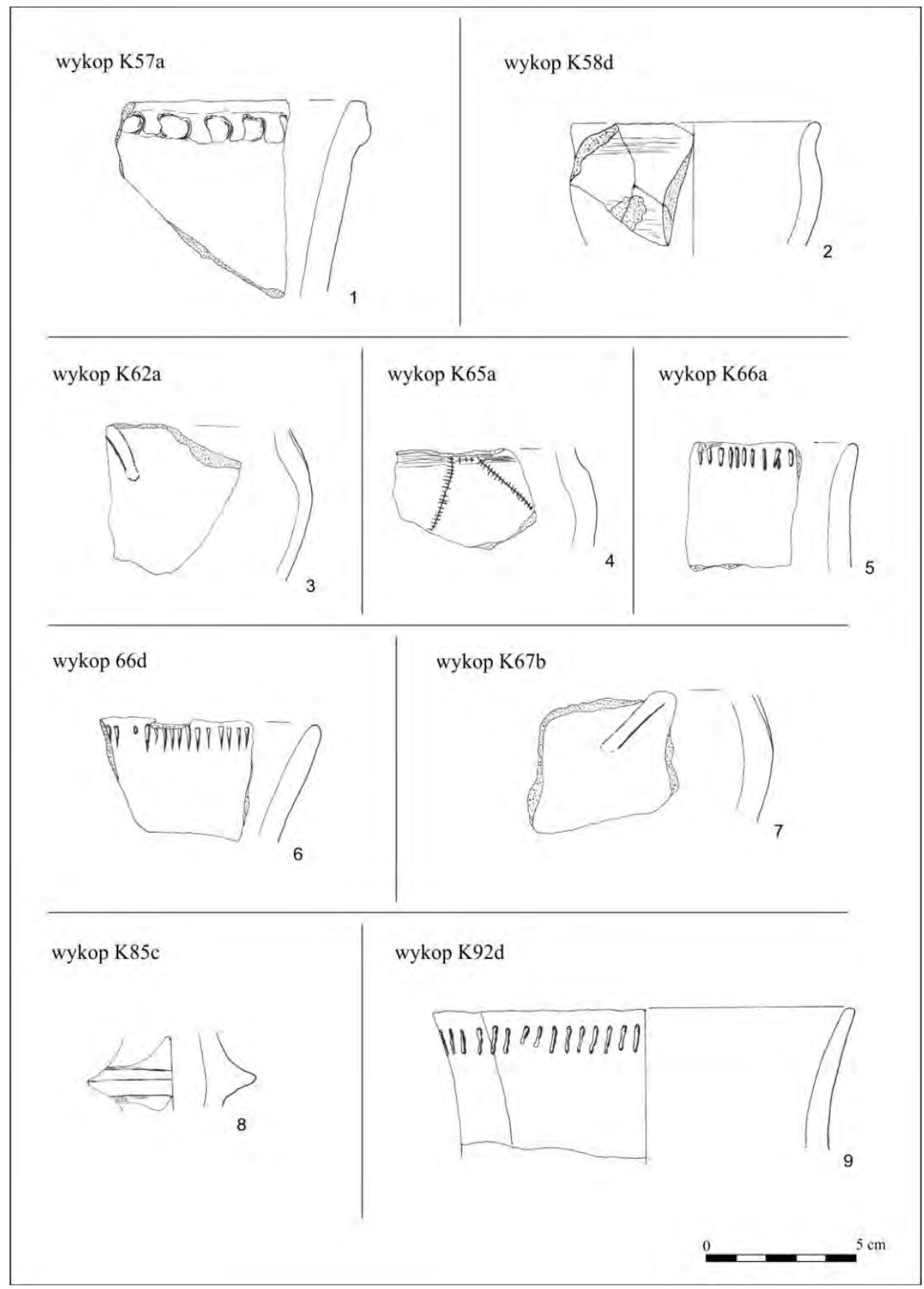

Ryc. 7. Polesie 1, gm. Łyszkowice. Wybór ceramiki kultury pucharów lejkowatych Fig. 7. Polesie 1, com. Łyszkowice. Selection of TRB pottery 
wykop K92d
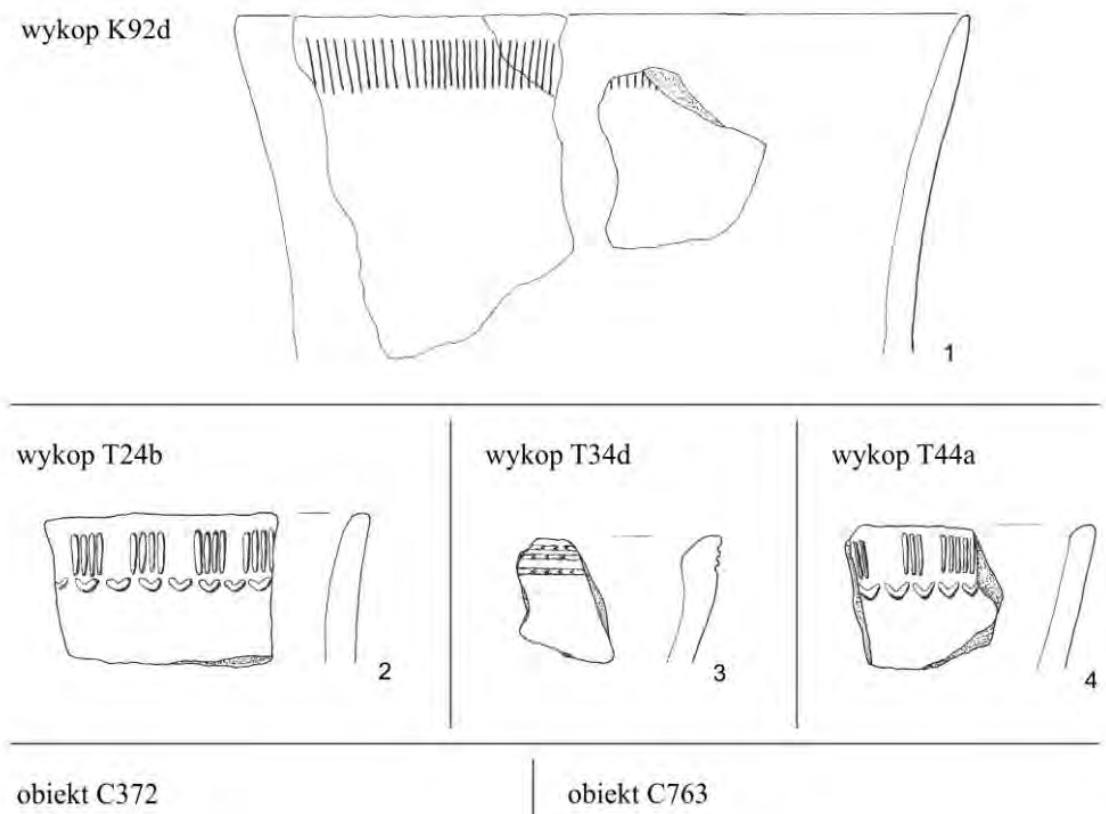

obiekt C763

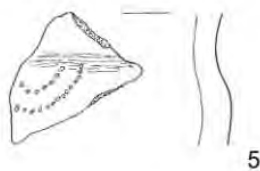

5

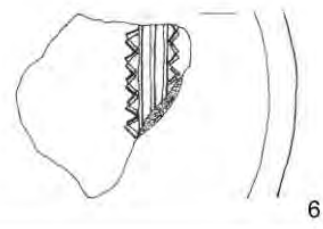

obiekt C848
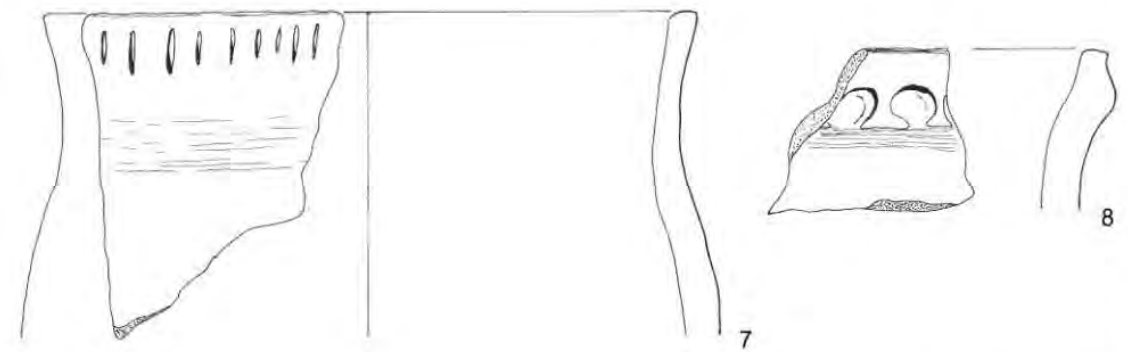

7

Ryc. 8. Polesie 1, gm. Łyszkowice. Wybór ceramiki kultury pucharów lejkowatych Fig. 8. Polesie 1, com. Łyszkowice. Selection of TRB pottery 
obiekt K527

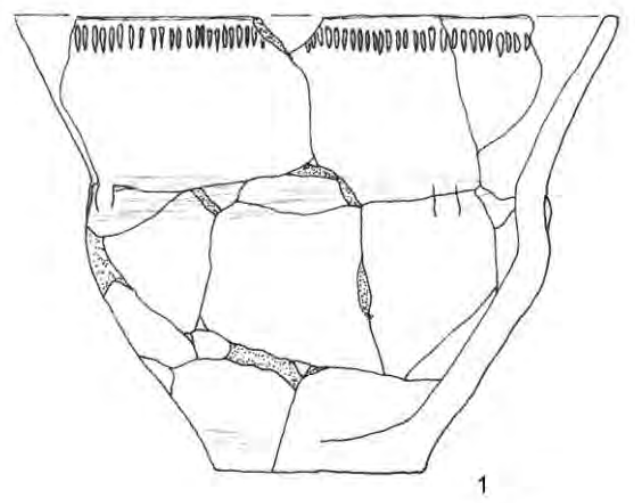

obiekt K769

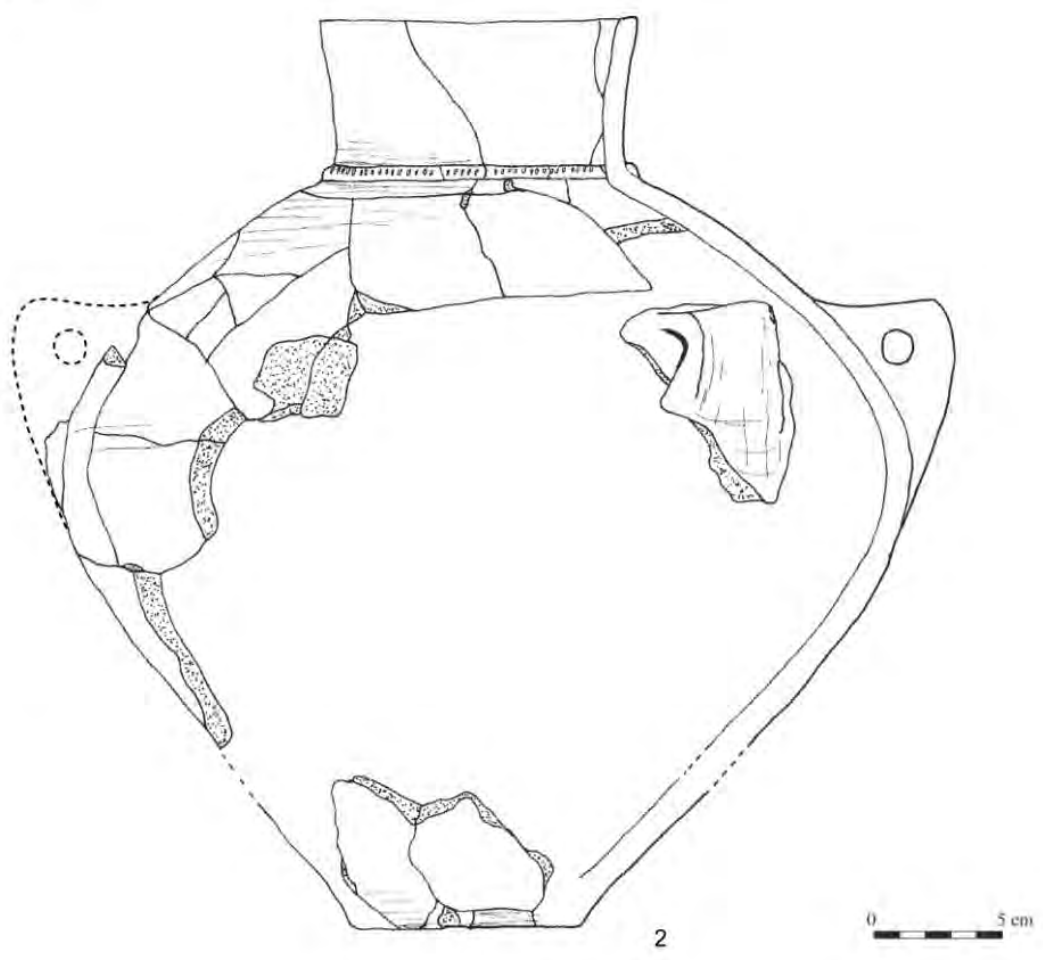

Ryc. 9. Polesie 1, gm. Łyszkowice. Wybór ceramiki kultury pucharów lejkowatych Fig. 9. Polesie 1, com. Łyszkowice. Selection of TRB pottery 

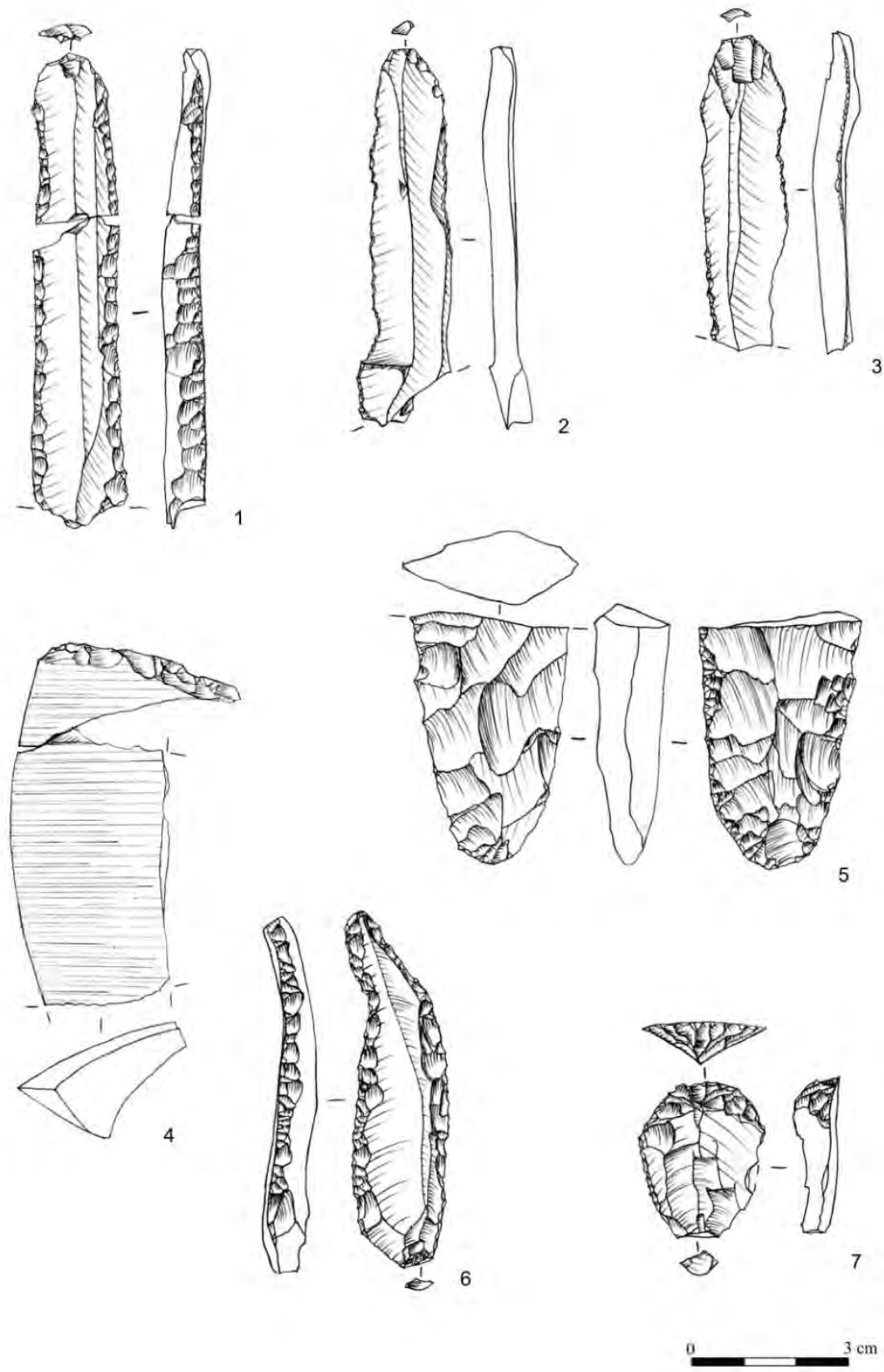

Ryc. 10. Polesie 1, gm. Łyszkowice. Wybór zabytków krzemiennych

Fig. 10. Polesie 1, com. Łyszkowice. Selection of flint artefacts 
Ornamenty były sporadycznie lokowane po wewnętrznej stronie wylewów (ryc. 4: 12), a tylko nieco częściej zdobiono wylewy (6 egzemplarzy; ryc. 3:1), pokrywając je karbami. Większość zdobień wystąpiła w strefie pod krawędziami naczyń (143 przypadki). Przeważa wśród nich ornamentyka najprostsza - oparta na odciskanych/nacinanych słupkach (96 egzemplarzy; np. ryc. 6:1-3). Niekiedy tworzyły one kompozycje wspólnie z zygzakami (np. ryc. 5:3, 9; 8:2, 4), choć te ostatnie występowały również samodzielnie (ryc. 3:1; 4:9). W omawianej strefie umieszczano również odciski palcowe, niekiedy na listwie plastycznej (np. ryc. 4:1, 10-11; 7:1). Brzuśce naczyń zdobiono rozmaitymi wersjami drabinek; wykonywano je w technice odciskania (ryc. 3:4) lub z użyciem rycia (ryc. 4:5). W tych partiach naczyń odnotowywano również ornamenty w postaci ,wsuwanych kątów - wielokrotnych zygzaków" realizowanych w technice rycia (ryc. 5:11) lub bruzdowej (ryc. 5:7). Do wykonania tych kompozycji używano również drabinek prętowych (ryc. 7:4). Ornamentyka plastyczna ogranicza się do listew (ryc. 3:7; 9:2), łuczków (ryc. 7:3, 7) i guzów (ryc. 4:10).

Z genetycznego punktu widzenia można identyfikować kilka warstw stylistycznych garncarstwa KPL ze stanowiska w Polesiu. Ich zrąb tworzą tradycje związane z grupą wschodnią, wśród których zwraca uwagę zdobnictwo nawiązujące do „wielkopolskiego baroku zdobniczego" (Chachlikowski 1994; Prinke, Weber 1982; Wierzbicki 2013) (np. ryc. 5:3, 7; 7:4; 8:2,4). Widoczne jest również piętno adaptacji wzornictwa południowego - związanego z małopolskimi społecznościami KPL (Kośko, Przybył 2004; Rzepecki 2014; por. np. Kulczycka-Leciejewiczowa 2002; Włodarczak 2006). Dotyczy to przede wszystkim zdobnictwa plastycznego w formie listew podkreślających załomy brzuśców (ryc. 3:7; 9:2) oraz guzów (ryc. 4:10). $\mathrm{Z}$ recepcją cech garncarstwa społeczności kultury niemeńskiej (Józwiak 2003) należy łączyć zdobienie w formie pasm ściegu bruzdowego wykonanego dość ostrym narzędziem (ryc. 8:3).

Przytoczona na wstępie diagnoza chronologiczna, wiążąca relikty osadnictwa KPL z Polesia $1 \mathrm{z}$ rozwiniętym etapem fazy wióreckiej znajduje potwierdzenie w dacie radiowęglowej uzyskanej dla kości zalegającej (na złożu wtórnym) w wy-

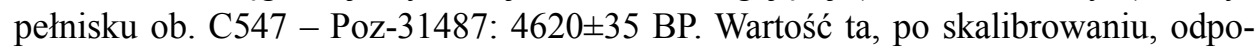
wiada okresowi 3512-3343 BC (95,4\%).

\section{KRZEMIENIE}

Charakter stanowiska bardzo ogranicza możliwość rozpoznania przynależności kulturowej egzemplarzy o formach banalnych (np. odłupki łuszczniowe - por. Domańska, Wąs 2010, 2011). Posługując się kryteriami stylistycznymi i surowcowymi, cytowani autorzy uznali, że bez wątpliwości z KPL można łączyć dość ograniczoną liczbę zabytków. Większość z nich została wykonana z surowców egzotycznych na 
Niżu. Trzeba tu zwrócić uwagę na 8 odłupków z siekier: 3 z nich reprezentują krzemień świeciechowski, a 5 pozostałych egzemplarzy - wołyński (ryc. 9:4). Również 3 spośród 4 drapaczy wykonano z importów; jest to w tym przypadku krzemień czekoladowy (ryc. 9:7). Surowca tego użyto także dla wykonania przekłuwacza (1 sztuka; ryc. 9:6). Krzemień czekoladowy (2 sztuki) i wołyński (7 sztuk) był również materiałem do produkcji wiórowców i wiórów retuszowanych (ryc. 9:1-3). Bardzo interesującym zabytkiem jest hipotetyczny fragment płoszcza wykonanego z krzemienia wołyńskiego (ryc. 9:5; Domańska, Wąs 2010).

\section{KULTURA PUCHARÓW LEJKOWATYCH W POLSCE ŚRODKOWEJ - KILKA UWAG DO DYSKUSJI}

Postęp prac nad rozpoznaniem cech osadnictwa KPL na terenach obecnego województwa łódzkiego jest wciąż głęboko niezadowalający (por. Pelisiak 1991, 2003; Wiklak 1975). Szerokopłaszczyznowe badania ratownicze nie przyniosły dotąd pod tym względem zasadniczej poprawy. Odnotowania wart jest jedynie zespół z Zabrzezia 1, gm. Rząśnia (Rzepecki 2003), stąd też niemal każdy dopływ informacji nabiera dużej wagi. Jest więc zrozumiałe, że mimo fatalnego stanu zachowania stanowiska również dane dotyczące Polesia 1 stanowią interesujący przyczynek do poznania KPL. Przed przystąpieniem do rozważań bardziej ogólnych warto zrekapitulować obserwacje dotyczące stanowiska analizowanego w tej pracy.

Relikty KPL odkryte w Polesiu 1 wyraźnie wskazują na intensywność oraz zróżnicowanie form osadnictwa. Prócz śladów efemerycznych obozowisk (np. hektary M, Q) odkryto pozostałości potwierdzające funkcjonowanie bardziej trwałych form zasiedlenia. Charakter materiałów z Polesia nie pozwala rzecz jasna na jednoznaczne rozstrzygnięcie co do doboru adekwatnego modelu (jedno- lub wielofazowego) tejże okupacji. Wydaje się jednak, że mamy w tym przypadku do czynienia z repliką rozwiązań znanych z Kujaw - tzn. rozległych, wielodomowych i stabilnych osad (Rzepecki 2014). Jak wiadomo, były one również osnową sieci osadniczej KPL w dorzeczu Grabi (Pelisiak 2003, s. 225) i na Pojezierzu Gostynińskim (Rybicka 2004). Podobnie „kujawski” charakter mają reguły produkcji ceramiki, której technologia, morfologia i zdobnictwo dobrze wpisują się w rozpoznane tam ramy. Diagnozie tej nie przeczy wyraźny udział elementów pochodzenia małopolskiego - czytelnych zarówno w ceramice, jak i charakterze wytwórczości krzemieniarskiej.

Powyżej rekonstruowany obraz wprowadza pewien dysonans poznawczy. Ogólnie należy się spodziewać, na podstawie współczesnych - bardzo niskich - ocen dotyczących efektywności gospodarki rolnej na terenach Polski środkowej, że w osadnictwie KPL przeważały tu dość mobilne formy wykorzystania środowiska (Nowak 2009, s. 302). Z perspektywy ogólnego mechanizmu szerzenia się KPL (Kośko 1981, s. 67-69) miał to być obszar refugialny w stosunku do Kujaw, co 
w garncarstwie skutkowało prowincjonalizmem i arytmią adaptacji cech pochodzenia pozaregionalnego (Chachlikowski 1994, s. 167). Oczekiwaniom teoretycznym nie odpowiadają jednak dane empiryczne, co wymusza modyfikację tych pierwszych.

Za punkt wyjścia dla procesów neolityzacji Polski środkowej należy uznać (za Aleksandrem Kośko - Kośko 1981, s. 68) ruchy kolonizacyjne, których centrum usytuowane było w strefie Kujaw - wschodniej Wielkopolski. Dane stylistyczne oraz oba znane wyniki datowań radiowęglowych (Polesie 1 oraz Zabrzezie 1 - zob. Domańska, Rzepecki 2006, s. 101) wskazują, że miało to związek z poziomem rozwiniętej fazy wióreckiej (ok. 3500-3300 BC). Osadnicy neolityczni przynieśli w pełni ukształtowany model kultury, który właściwie nie wykazuje cech endemicznych. Brakuje również jednoznacznych wskaźników masowego udziału w jego przetwarzaniu lokalnej ludności mezolitycznej (lub postmezolitycznej). Integralność tego pakietu źródeł wskazuje nie na prowincjonalizm, lecz na intensywność więzi z obszarami wyjściowymi. Wykazując zasadniczą łączność lokalnych społeczności KPL z areałem kulturowym grupy wschodniej, można określić jednocześnie symptomy ich wyjątkowej, akwizycyjnej roli w dystrybucji wzorców proweniencji małopolskiej (Rzepecki, 2003). W tym ujęciu „puchary lejkowate” z terenów Polski środkowej były aktywnym kooperantem grup KPL zasiedlających stare enklawy rolnictwa neolitycznego, tzn. Kujawy i Małopolskę.

\section{BIBLIOGRAFIA}

Bailey G.

2007 Time Perspectives, Palimpsests and the Archaeology of Time. Journal of Anthropological Archaeology, 26, s. 198-223.

Balcer B.

2012 Budownictwo mieszkalne i gospodarcze w neolicie ziem Polski. Warszawa: Instytut Archeologii i Etnologii Polskiej Akademii Nauk.

Chachlikowski P.

1994 Osiedla kultury pucharów lejkowatych w Podgaju, woj. wlocławskie, stanowisko 6A.

Poznań: Uniwersytet im. Adama Mickiewicza w Poznaniu.

Domańska L., Rzepecki S.

$2008 \quad$ Z badań nad recepcją południowo-wschodnich wzorców kulturowych w wielkodolinnych społecznościach kultury pucharów lejkowatych. W: J. Bednarczyk, J. Czebreszuk, P. Makarowicz, M. Szmyt (red.), Na pograniczu światów. Studia z pradziejów międzymorza baltycko-pontyjskiego ofiarowane Profesorowi Aleksandrowi Kośko w 60. rocznicę urodzin (s. 93-104). Poznań: Wydawnictwo Poznańskie.

Domańska L., Rzepecki S., Makarowicz P., Górski J., Wawrusiewicz A., Solecki Ł., Kot K., Piotrowska M., Ficyk M., Wąs M.

2012 Wyniki ratowniczych badań wykopaliskowych przeprowadzonych w latach 2005-2008 na stanowisku Polesie 1, gm. Łyszkowice, woj. łódzkie. W: Raport 2007-2008 (t. 1, s. 183-214). Warszawa: Narodowy Instytut Dziedzictwa. 
Domańska L., Wąs M.

2010 Materiały krzemienne ze stanowiska Polesie 1, gm. Łyszkowice, pow. Łowicz. W: L. Domańska, S. Rzepecki (red.), Opracowanie wyników archeologicznych badań ratowniczych na stanowisku Polesie 1, gm. Łyszkowice, t. 2, Epoka kamienia. [Maszynopis w zbiorach Narodowego Instytutu Dziedzictwa (s. 3-30), Warszawa].

Domańska L., Wąs M.

2011 Materiały krzemienne trzcinieckiego kręgu kulturowego ze stanowiska Polesie 1, gm. Łyszkowice, woj. łódzkie. W: J. Górski, P. Makarowicz, A. Wawrusiewicz, Osady i cmentarzyska społeczności trzcinieckiego kręgu kulturowego w Polesiu, stanowisko 1, woj. łódzkie (s. 276-283). Łódź: Instytut Archeologii Uniwersytetu Łódzkiego, Fundacja Uniwersytetu Łódzkiego.

Górski J., Makarowicz P., Wawrusiewicz A.

2011 Osady i cmentarzyska społeczności trzcinieckiego kręgu kulturowego w Polesiu, stanowisko 1, woj. łódzkie. Łódź: Instytut Archeologii Uniwersytetu Łódzkiego, Fundacja Uniwersytetu Łódzkiego.

Józwiak B.

2003 Społeczności subneolitu wschodnioeuropejskiego na Niżu Polskim w międzyrzeczu Odry $i$ Wisty. Poznań: Uniwersytet im. Adama Mickiewicza w Poznaniu.

Kośko A.

1981 Udziat poludniowo-wschodnioeuropejskich wzorców kulturowych $w$ rozwoju niżowych społeczeństw kultury pucharów lejkowatych. Grupa mątewska. Poznań: Uniwersytet im. Adama Mickiewicza w Poznaniu.

Kośko A., Przybył A.

2004 Kultura pucharów lejkowatych. W: J. Bednarczyk, A. Kośko (red.), Od najdtuższego domu najstarszych rolników do dworu staropolskiego. Wyniki badań archeologicznych na trasach gazociagów Mogilno-Włocławek i Mogilno-Wydartowo (s. 235-313). Poznań: Wydawnictwo Poznańskie.

Kośko A., Szmyt M.

2006 Opatowice - Wzgórze Prokopiaka I. Poznań: Wydawnictwo Poznańskie.

Kulczycka-Leciejewiczowa A.

2002 Zawarża. Osiedle neolityczne w poludniowopolskiej strefie lessowej. Wrocław: Instytut Archeologii i Etnologii Polskiej Akademii Nauk.

Nowak M.

2009 Drugi etap neolityzacji ziem polskich. Kraków: Instytut Archeologii Uniwersytetu Jagiellońskiego.

Pelisiak A.

1991 The Funnel Beaker Culture in Central Poland. W: D. Jankowska (red.), Die Trichterbecherkultur. Neue Forschungen und Hypothesen (s. 159-162). Poznań: Instytut Prahistorii Uniwersytetu im. Adama Mickiewicza w Poznaniu, Zakład Archeologii Wielkopolski IHKM w Poznaniu.

Pelisiak A.

2003 Osadnictwo. Gospodarka. Spoleczeństwo. Studia nad kultura pucharów lejkowatych na Niżu Polskim. Rzeszów: Wydawnictwo Uniwersytetu Rzeszowskiego.

Prinke D., Weber A.

1982 Konary, gm. Dąbrowa Biskupia, woj. Bydgoszcz, stan. 6A-6B (przyczynek do studiów nad „centralnokujawskim” nurtem technologicznego i stylistycznego rozwoju ceramiki kultury pucharów lejkowatych). Sprawozdania Archeologiczne, 34, s. 25-51. 
Rybicka M.

2004 Kultura pucharów lejkowatych na Pojezierzu Gostynińskim. Chronologia. Osadnictwo. Gospodarka. Łęczyca: Muzeum w Łęczycy.

Rzepecki S.

2003 Osadnictwo kultury pucharów lejkowatych. W: L. Czerniak (red.), Badania archeologiczne na terenie odkrywki „Szczerców” Kopalni Węgla Brunatnego „Bełchatów” S.A. (t. 3, s. 245-286). Poznań: Centrum Archeologicznych Badań Ratowniczych Sp. z o.o. w likwidacji, Fundacja Uniwersytetu im. Adama Mickiewicza w Poznaniu.

Rzepecki S.

2014a Wilkostowo 23/24. Neolityczny kompleks osadniczy. Łódź: Instytut Archeologii Uniwersytetu Łódzkiego, Fundacja Uniwersytetu Łódzkiego.

Rzepecki S.

2014b Palimpsest, time perspectivism and megaliths. Sprawozdania Archeologiczne, 66, s. 9-27.

Twardy J., Forysiak J.

2011 Charakterystyka środowiska geograficznego okolic stanowiska archeologicznego Polesie 1 oraz neoholoceńskie zmiany jego budowy geologicznej i rzeźby. W: J. Górski, P. Makarowicz, A. Wawrusiewicz, Osady i cmentarzyska społeczności trzcinieckiego kręgu kulturowego w Polesiu, stanowisko 1, woj. łódzkie (s. 227-250). Łódź: Instytut Archeologii Uniwersytetu Łódzkiego, Fundacja Uniwersytetu Łódzkiego.

Wierzbicki J.

2013 Wielka kolonizacja. Społeczności kultury pucharów lejkowatych $w$ dorzeczu środkowej Warty. Poznań: Stowarzyszenie Naukowe Archeologów Polskich, Oddział w Poznaniu.

Wiklak H.

1975 Neolit w Polsce środkowej. Prace i Materiały Muzeum Archeologicznego i Etnograficznego $w$ Lodzi. Seria Archeologiczna, 22, s. 67-99.

Włodarczak P.

2006 Chronologia grupy południowo-wschodniej kultury pucharów lejkowatych w świetle dat radiowęglowych. W: J. Libera, K. Tunia (red.), Idea megalityczna $w$ obrzadku pogrzebowym kultury pucharów lejkowatych (s. 27-66). Lublin-Kraków: Instytut Archeologii i Etnologii Polskiej Akademii Nauk, Oddział w Krakowie, Instytut Archeologii Uniwersytetu Marii Curie-Skłodowskiej w Lublinie.

\section{STUDY OF NEOLITHISATION OF CENTRAL POLAND. REMAINS OF THE FUNNEL BEAKER CULTURE SETTLEMENT FROM SITE POLESIE 1, COM. ŁYSZKOWICE}

Su m mary

The geology of the area occupied by the site and intensity of prehistoric and historic occupation contributed to the dynamic course of slope erosion and deflation processes. As a result, the site represents a perfect example of an archaeological palimpsest, where successive episodes of human activity deformed and irreversibly destroyed remnants of former settlement. 
The vast majority of the Funnel Beaker culture (hereinafter referred to as TRB from German Trichterbecherkultur) materials (approx. 95\% of pottery) was recorded outside the features, in subsurficial soil level. Also, observed areas with concentrations of pottery (Fig. 1) might only be considered an approximation of the original distribution of concentrations. However, it could be assumed that they represent the remains of a settlement (sections $\mathrm{C}$ and $\mathrm{K}$ ) and camps (e.g. hectare M). Thirteen features should be linked to the TRB settlement (Fig. 2) representing the following functional categories: houses (C1035), storage pits (K769) and pits of undetermined function (C16, C741, K334, K527, K742, K573, K623, KK782, K783, K171, K587). They all occurred in hectares $\mathrm{C}$ and $\mathrm{K}$ (Fig. 2).

At the site there have been 3676 fragments of pottery discovered of the TRB culture, with a total weight of $46972 \mathrm{~g}$. In view of the convention of the text, their presentation will be limited to the most important features of this assemblage.

Significant fragmentation does not allow for a complete reconstruction of the vessel forms. However, it seem sufficient to emphasise the presence of funnel beakers (e.g. Fig. 6:2, 4; 9:1), mortar-shaped beakers (Fig. 5:13) and amphorae (Fig. 3:7; 9:2), as well as a flask with an orifice (Fig. 7:8), pots (Fig. 4: 108: 7) and bowls/vases (Fig. 7:2). They form a collection fairly well documented for a developed stage of the Wiórek phase of the eastern TRB. With this diagnosis corresponds ornamentation known from 186 fragments of vessels and radiocarbon dating (Poz-31487: $4620 \pm 35 \mathrm{BP})$, the latter calibrated corresponding with the period of 3512-3343 BC (95.4\%).

Also a small assemblage of flint implements should be interpreted as the TRB one, with its mainly imported raw materials: Świeciechów, Volhynian and chocolate flints (Fig. 9).

The author links the appearance of the TRB settlement at the site with the process of colonisation of central Poland by communities arriving from Kujawy and eastern Wielkopolska. A special feature of settlers from Wilkostów was their participation in the process of maintaining ties with the TRB communities from Małopolska. 